\title{
A QUANTITATIVE TEST OF UPPER EXTREMITY FUNCTION
}

\author{
Douglas Carroll, M.D. \\ Department of Physical Medicine and Rehabilitation, Baltimore City Hospital, Baltimore, Md.
}

(Received 1 July 1964)

IN A number of clinical situations, there is a need for a simple semi-quantitative test of upper extremity function. Measurement of function is of particular importance in evaluating the results of hand surgery and upper extremity prosthesis, in following the development of hand deformities in rheumatoid arthritis and neurological diseases, and in judging the effectiveness of different forms of therapy.

It must be kept clearly in mind that the test we are trying to develop is one which will have direct relationship to what the patient is able to do in every-day activities. Measurement of individual muscle strength and joint range of motion gives some idea of what the patient may be able to use his hands for, but the ingenuity and use of muscle substitution seen in chronic hand disabilities makes prediction of upper extremity function from muscle tests and range of motion tests inaccurate. Clinical observation and prosthetic research [1,2] have shown that there are certain movements of the upper extremity which are of more value than others. To be sure, finger performance is of little functional value unless there is arm and shoulder stability and movement. It is also true that shoulder and arm function are of little use without finger movement.

The upper extremity evaluation test described in this communication is simple and quick enough to be carried out in an outpatient department or office by the doctor or technician. A simple scoring method is used so that results can be compared at different time intervals. The assumption is made that complex upper extremity movements used in daily activities can be reduced to certain patterns of grasp, pinch and grip of the hand; supination and pronation of the forearm: extension and flexion of the elbow; and elevation of the arm.

\section{Preliminary experiments}

About 200 upper extremities with traumatic, neurological and arthritic impairments were examined, using various series of tests until the testing procedure described below was adopted.

The principal concern in the development of the testing procedure was whether it was representative of the major activities of the upper extremity in everyday activities of daily living. The test was designed to measure the patient's ability to perform arm and hand activities of a general nature used in ordinary daily living. We were not attempting primarily to measure skill, speed, strength, coordination, endurance, sensation, sight, vocational potential, joint range or muscle strength grades. Most of these factors, nevertheless, played some part in performing most of the sub-tests. 
When the testing procedure was nearly in its present form, it was compared with a conventional upper extremity activities of daily living function test. The latter included forty activities having to do with eating, washing, dressing, toilet, writing, exchanging money, telephoning, turning on lights and opening doors. These were scored from zero to four. The endpoints used to differentiate scoring grades on the conventional activities of daily living form could not be set as definitely as on

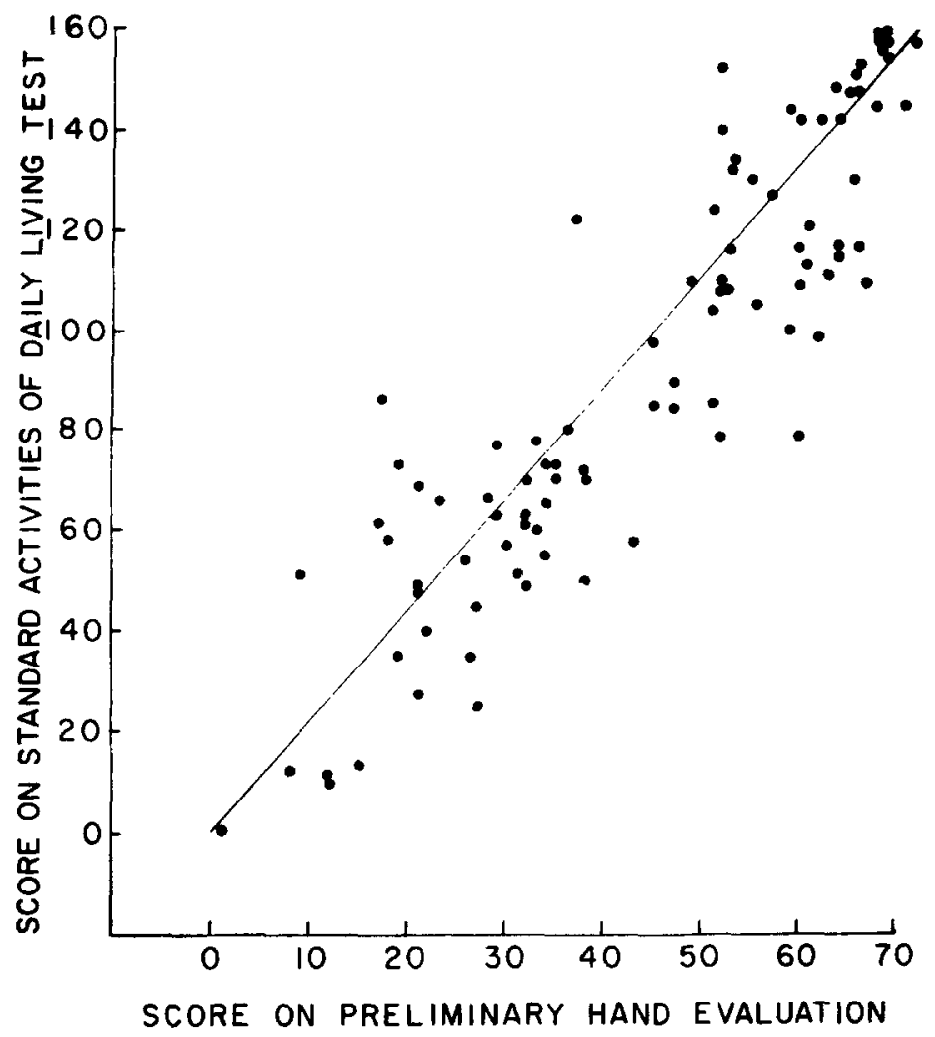

Fig. 1. Comparison of scores on 93 upper extremities tested with both preliminary hand evaluation (based on tests for grasp, pincli and grip of the hand, supination and pronation of the forearm, extension and flexion of the elbow, and elevation of the arm) and a conventional activities of daily living test for upper extremities.

the hand function evaluation, since the activities were less stereotyped*. We do not consider such qualitative data subject to statistical analysis and are satisfied that the hand function evaluation score gives a good indication of overall hand function in the activities of daily living (Fig. 1).

\footnotetext{
*In this series of experiments, the hand function evaluation was based on a five point scoring system : 0 for no performance of any part of the test; 1 for partial completion; 2 for complete performance, but with great difficulty; 3 for complete performance with very slight abnormality; and 4 for normal performance. This scoring system was subsequently abandoned because of difficulties in defining end points between scores of 2,3 and 4 . In this experiment only 18 subtests of the present 33 were used.
} 
Having established that the total score on the preliminary upper extremity evaluation test would give a rough estimate or prediction of what the patient might be able to do with the hand in daily use, efforts were made to improve the reliability and repeatability of the testing procedure. The number of grades was reduced from five to four, resulting in easier differentiation between grades. This change resulted in better observer agreement in scoring. On the preliminary test, individual fingers had not been tested in pinch. It became clear that pinch of each finger was of crucial importance in overall hand function, so that on the final test (Table 1) each finger was tested for pinch individually on a series of different sized spheres.

With the test in final form (Table 1), it was then possible to apply it to a number of patients to estimate reliability, repeatability and its place in the overall function of a series of patients with chronic impairments.

\section{Description of upper extremity function test (U.E.F.T.)}

The evaluation consists of moving objects to a shelf, placing them over a peg, writing the name, placing the hand to mouth, head, neck and mouth, and pouring water from a pitcher or glass. The objects are of different shapes and weights designed to test grasp, grip, pinch, placing, arm extension and elevation, pronation and supination, and, to a lesser extent, strength. The apparatus consists of a $17 \frac{1}{2} \times 28 \frac{1}{2} \mathrm{in}$. wooden table whose surface is $30 \frac{3}{4} \mathrm{in}$. from the floor. The table is arranged to contain the objects used in the evaluation. A shelf $3 \frac{3}{4}$ in. wide is mounted at the back of the table, with its surface $14 \frac{3}{4}$ in. above the table surface.

Table 2 describes the objects which are to be moved. Fig. 2 is a top view of the evaluation platform. The numbers designating positions correspond to the numbers designating the objects; numerals followed by A designate positions to which the objects are to be moved.

\section{Detailed description}

Positions 1, 2, 3 and 4 are compartments for containing the wooden blocks. In general, the compartments are made by tacking strips of wood to the table as shown in Fig. 2. The strips are approximately $\frac{3}{4}$ in. wide by $\frac{3}{8}$ in. high. The blocks are to be lifted to the shelf at positions $1 \mathrm{~A}$ through $4 \mathrm{~A}$.

Position 5 is a wooden peg 5 in. in height and $\frac{3}{4}$ in. in diameter, over which is placed the large iron pipe. The pipe is gripped and moved to position 5A, a $\frac{3}{4}$ in. bolt protruding $3 \frac{1}{4}$ in. from a $2 \times 4$ in. plank mounted at the rear of the platform.

Position 6 is a $\frac{1}{4}$ in. bolt (head removed) protruding 2 in. from the table, on which is placed the small iron pipe. The pipe is gripped and moved to position $6 \mathrm{~A}$, a similar $\frac{1}{4}$ in. bolt protruding $2 \frac{1}{2}$ in. from the $2 \times 4$ in. plank.

There is no compartment at position 7 . The slate is placed on the table to be picked up by the patient.

At positions 8-13 there is a tray (tobacco tin lid), 5 in. in diameter with a rim about $\frac{3}{8}$ in. high, to contain the spheres and the stecl washer. The spheres are to be moved to a similar tray on the shelf. The steel washer is placed over a finishing nail protruding $3 \mathrm{in}$. from the table at position $13 \mathrm{~A}$.

Item 14 is an iron placed flat on the table. It is to be moved to the shelf where it may be placed in any position.

Items 15 and 16 are tumblers. Item 17 is a water pitcher. Water is poured from 
TABLe 1. Form USEd IN UPPER EXTRemity Function Test (U.E.F.T.)

Date.

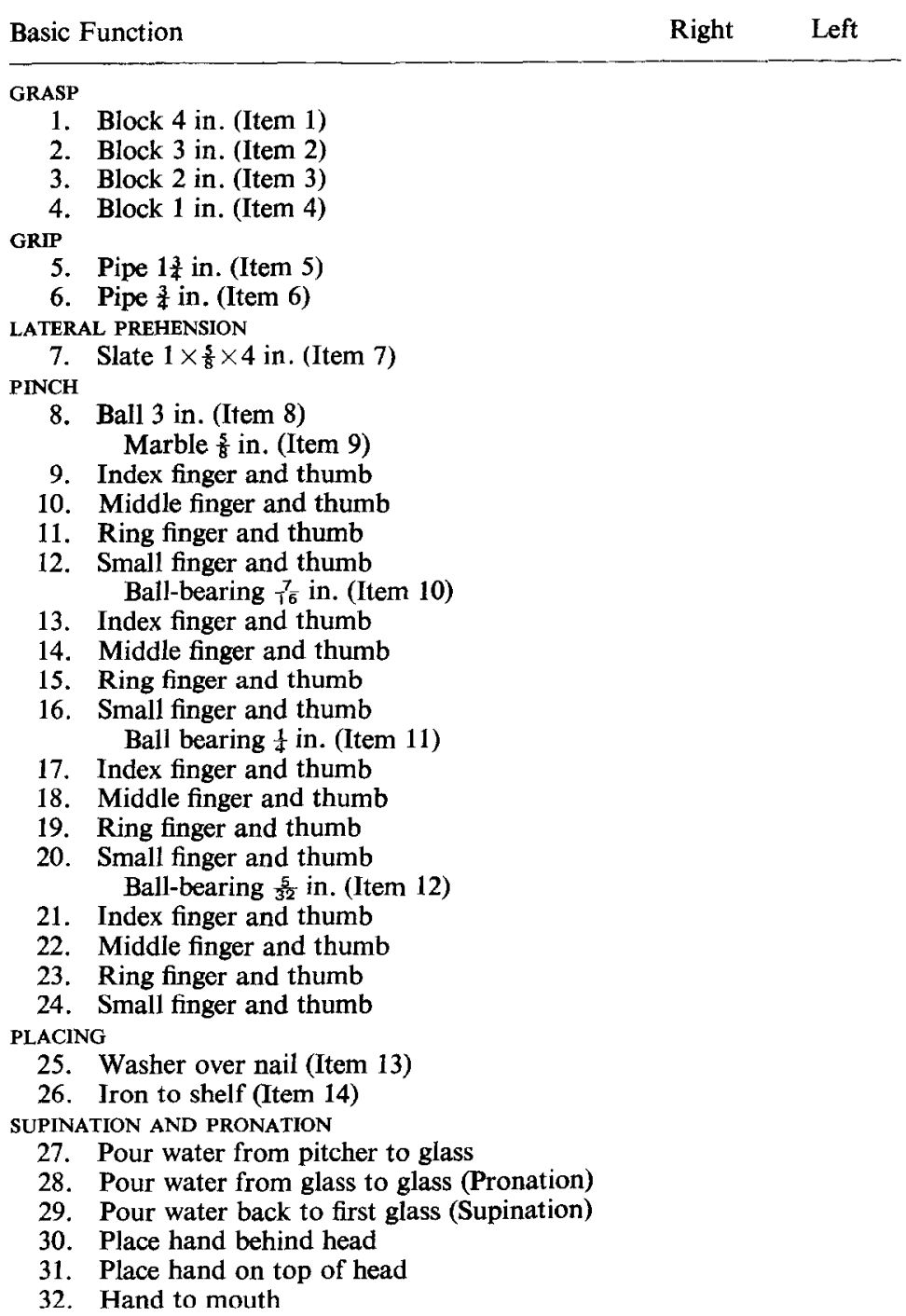

33. Write name

TOTAL

Smedley Dynamometer Reading:

Does pain interfere with function?

Scoring: 3-Performs test normally.

2-Completes test, but takes abnormally long time or has great difficulty.

1-Performs test partially.

0 - Can perform no part of test. 
the pitcher into one of the tumblers. The water is then poured from the tumbler into a second tumbler using a motion involving pronation of the hand. The water is then poured back into the first tumbler using a motion involving supination of the hand.

TABLE 2. OBJECTS USED IN TEST

\begin{tabular}{|c|c|c|c|}
\hline Number & Description & $\begin{array}{l}\text { Dimensions* } \\
\text { (in.) }\end{array}$ & $\begin{array}{l}\text { Mass } \\
(\mathrm{g})\end{array}$ \\
\hline 1. & Wooden cube & $4 \times 4 \times 4$ & 576 \\
\hline 2. & Wooden cube & $3 \times 3 \times 3$ & 243 \\
\hline 3. & Wooden cube & $2 \times 2 \times 2$ & 72 \\
\hline 4. & Wooden cube & $1 \times 1 \times 1$ & 9 \\
\hline 5. & Large iron pipe & $1 \frac{5}{8}$ O.D. $\times 6 \frac{1}{8}$ & 500 \\
\hline 6. & Small iron pipe & $\frac{7}{8}$ O.D. $\times 4 \frac{1}{8}$ & 125 \\
\hline 7. & Slate & $4 \frac{1}{4} \times 1 \times \frac{3}{8}$ & 61 \\
\hline 8. & Wooden ball & 3 O.D. & 100 \\
\hline 9. & Glass marble & $\frac{5}{8}$ O.D. & 6.3 \\
\hline 10. & Metal sphere & $\frac{7}{16}$ O.D. & 6.6 \\
\hline 11. & Metal sphere & $\frac{1}{4}$ O.D. & 1.0 \\
\hline 12. & Metal sphere & $\frac{5}{32}$ O.D. & 0.34 \\
\hline 13. & Steel washer & $\frac{3}{32}$ thick $\times 1 \frac{3}{8}$ O.D. $\times$ & 14.5 \\
\hline 14. & Iron & $6 \mathrm{lb}$ approx. & \\
\hline 15. & Plastic tumbler & 8 fl. oz capacity & \\
\hline 16. & Plastic tumbler & 8 fl. oz capacity & \\
\hline 17. & Aluminum water pitcher & 3 qt capacity & \\
\hline 18. & Pencil & & \\
\hline
\end{tabular}

*O.D. = Outside diameter; I.D. = Inside diameter.

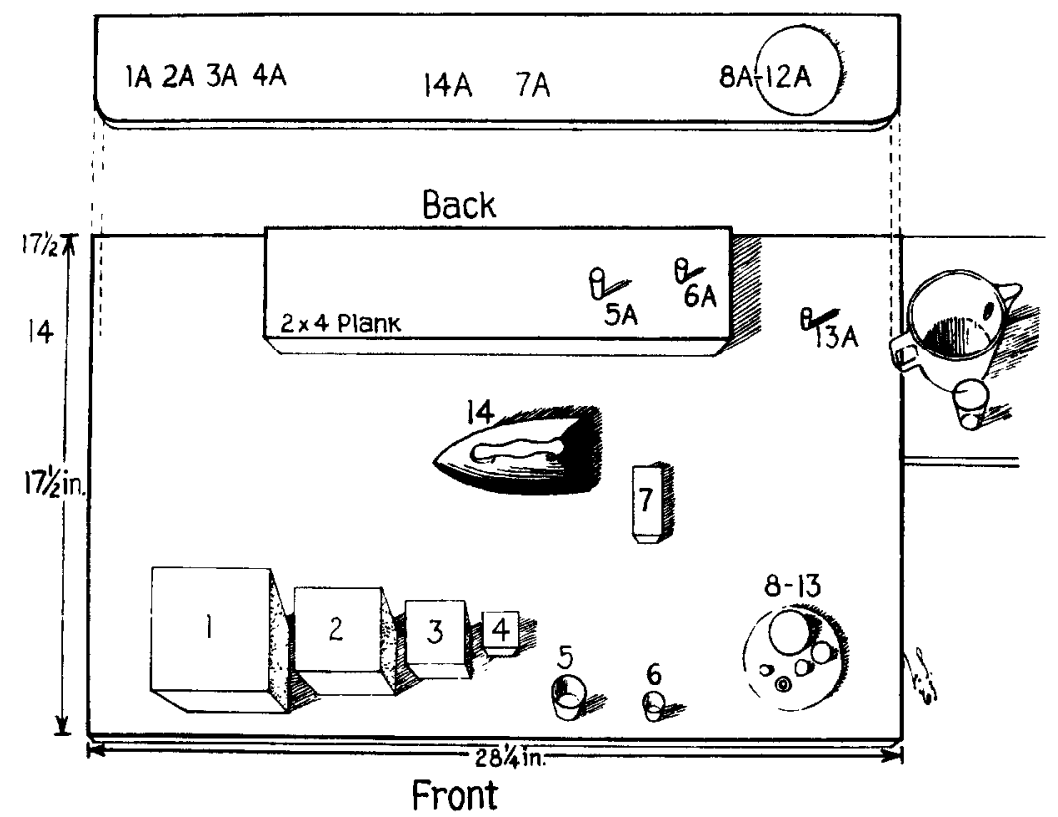

FIG. 2. Top view of evaluation platform. The shelf (attached by broken line) is located $14 \frac{3}{4}$ inches above the table surface. Items to be moved are numbered 1 to 14 and positions to which they are to be moved are numbered $1 \mathrm{~A}$ to $14 \mathrm{~A}$. 


\section{Performance and grading}

The patient is placed in a chair in a comfortable position in front of the table. He may be as close to the table as he finds necessary to perform the tests and may move along the table if this movement is helpful. The patient is not allowed to lift himself from the chair during the test, although he may roll to one side. Each hand is tested separately. The tester explains the tests until the patient clearly understands what is expected. With some patients it may be necessary to demonstrate each test separately as the evaluation is being performed.

There are four grades for each of the 33 tests of the total evaluation:

Grade 3. The test is performed normally.

Grade 2. The test is completed, but slowly or very clumsily. Completion of the test consists of placing the test item in the correct position, pouring the water, placing the hand in the indicated position, or writing the name.

Grade 1. The patient completes part of the test. This grade is given when the patient is able to pick up or lift the item from the table or from its slot, but is unable to place the object in its correct position. In items 27 to 29 , the patient is able to lift the pitcher or glass but unable to pour water into its proper receptacle. Item 33 consists of writing the name with the dominant hand. The patient is given a grade 1 if he can hold a pencil in the hand, but cannot write legibly.

Grade 0 . The patient is unable to perform any part of the test. Pushing objects out of their slots or around the table is graded 0 .

The total score is added (Table 1). Since part of the score consists of writing the name with the dominant hand, maximal score for the right hand is 99 and for the left hand 96.

\section{Evaluation of the testing procedure}

Having developed the Upper Extremity Function Test (U.E.F.T.) to this stage, it was then used in a survey of a large number of nursing home patients with upper extremity disorders in addition to other physical and mental impairments. This survey was expected to yield estimates on the number of patients with upper extremity impairments and the severity of the impairment. These data, taken together with the diagnosis, a mental status evaluation [3] and an activities of daily living estimate [4], should allow an appraisal of the relative importance of the upper extremity impairment in the patient's total disability.

Because the patients had stable disabilitics, it was also possible to do the U.E.F.T. serially to test its repeatability and to have it performed by two different observers independently to test agreement in scoring between different observers.

\section{Methods}

Each patient was examined to establish the diagnosis of the upper extremity disease. A Mental Status Check List [3] and Activities of Daily Living Form [4] were completed and the U.E.F.T. was carried out on each upper extremity of the selected patients.

\section{Material}

The Baltimore City Hospital Infirmary has facilities for 278 ambulatory elderly 
people and for 328 patients who have received optimal medical care and are awaiting transfer to a nursing home. All patients with upper extremity impairments were studied and 79 were found, amongst whom there were 120 abnormal upper extremities.

Of these 79 patients, 37 had both hands involved by the same process, such as rheumatoid arthritis, peripheral neuritis, systemic sclerosis, cord injuries, muscular dystrophy, Parkinson's disease, disseminated sclerosis, and other neurological diseases; 38 patients had one hand involved, usually by hemiplegia or trauma. Four patients had their arms involved by different processes; one had a left hemiplegia and a right Colles' fracture; one had a right hemiplegia and an amputation of the left small finger; one had peripheral neuritis with a right hemiplegia; and one had bilateral rheumatoid arthritis with a right hemiplegia. When more than one process involved an extremity, the case was listed under "Other" in Tables 3 and 4. The total number of abnormal upper extremities was 120.

\section{R E S U L T S}

Diagnoses, age, sex, type of onset and duration of impairment of upper extremity impairment. The findings reflect the population of the Baltimore City Hospital Infirmary. Most of the patients are elderly, without social resources and with major systemic diseases. Patients with isolated upper extremity disabilities do not accumulate in such a facility. Table 3 shows that hemiplegia was the most common impairment. Right hemiplegias (22) were slightly more common than left hemiplegias (14). More females (6) than males (2) had rheumatoid arthritis. The patients were in the older age group. The majority had the impairment for more than a year.

Activities of Daily Living, Mental Status Check List, Upper Extremity Evaluation Scores, and Smedley Dynamometer Scores (Table 4).

1. The Activities of Daily Living Score: This scoring system evaluates the patient's ability to care for himself. Patients with a score from 95 to 100 are generally able to ambulate, feed, dress, perform personal toilet, are not incontinent, can communicate well and have no contractures limiting the performance of daily activities. Only 18 of the 79 patients were fully independent. Four required full nursing care, and the remainder were partially self-sufficient.

2. The Mental Status Check List: This list of questions tests the patient's orientation, ability to subtract, interpretation of simple proverbs, and familiarity with current events. Scores above 30 suggest that the patient has sufficient mental facilities to follow directions and learn simple tasks. Scores below 30 usually mean that the patient has some degree of disorientation. Of the 79 patients, 7 were completely disoriented, 38 had scores less than 30 , the remainder greater than 30 .

3. Upper Extremity Function Test: The scores were divided into six functional groups: Trace (scores between 0 and 25), very poor (26-50), poor (51-75), partial (76-89), functional (90-98) and maximal (scores of 99 for the dominant hand and 96 for the non-dominant hand). Tests showed that 24 hands had 'trace' of function, 35 'very poor' function, 26 'poor' function, 13 'partial' function, 21 had 'functional' hands and one had 'maximal' function.

4. Smedley Dynamometer Readings: Nearly all impaired hands demonstrated weakness of grip as measured by the Smedley Dynamometer. 


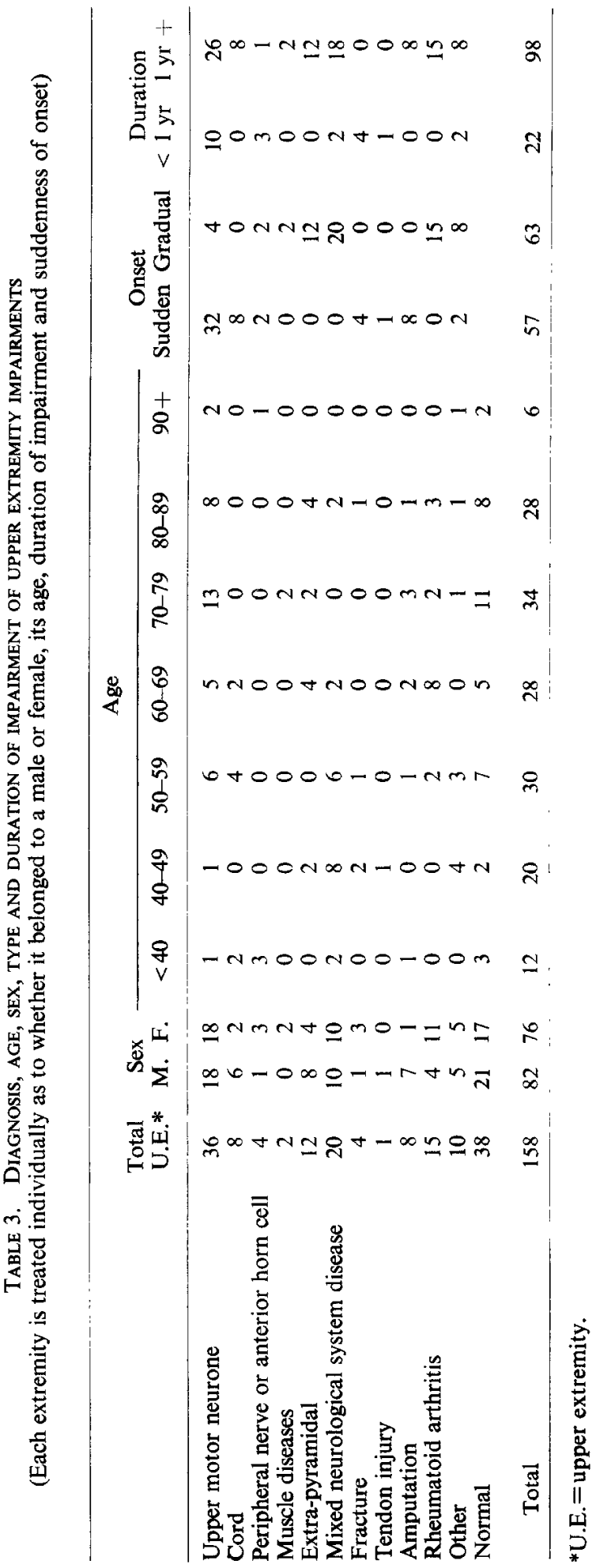




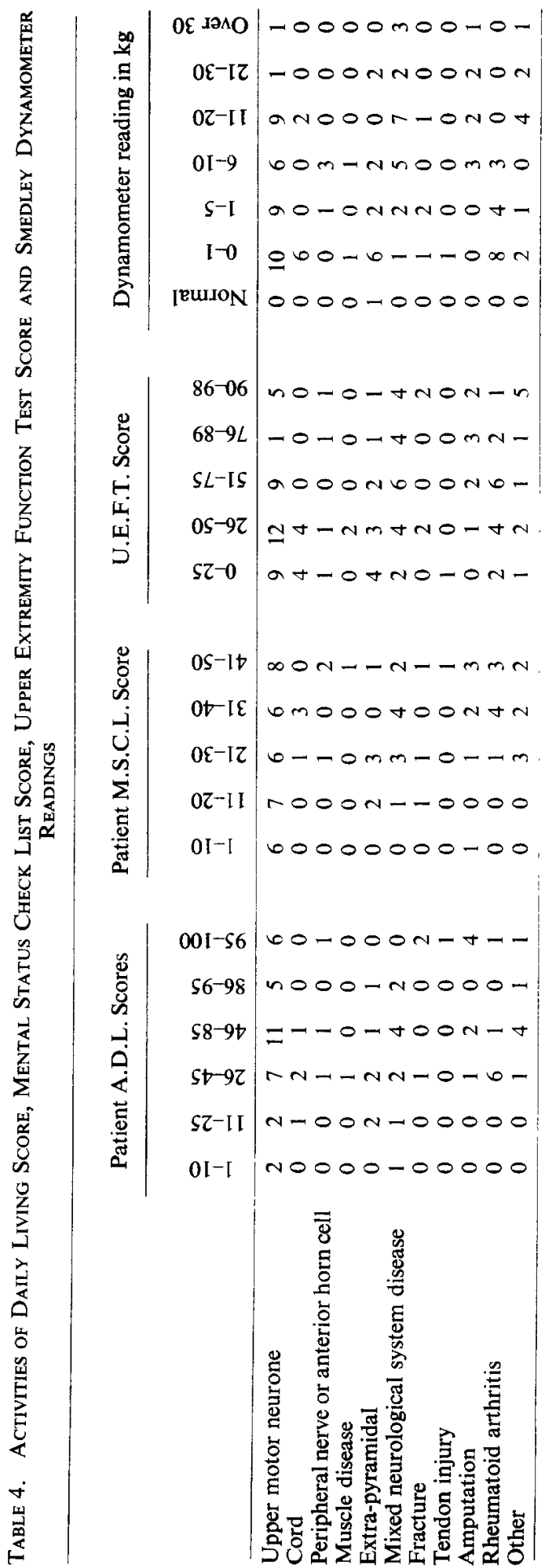


Changes in score with serial evaluation. Without knowledge of the previous score, 30 hands were re-tested a month later. Of these, 7 hands were normal clinically and by test. The other 23 had chronic stable hand impairments clinically. Scores on the 7 normal hands were identical at the two testing periods. Of the tests with chronic stable hand impairments, the total score was identical in one case; there was a difference of one point in 5 cases; two points in 5 cases; three points in 7 cases; five points in 2 cases, six points, seven points and eight points in one case each.

Observer differences in test performance. Two experienced observers independently made 48 individual hand evaluations and scored them. There were 22 identical total scores, 10 differed by one point, 4 by two points, 5 by three points, 4 by four points and 3 by five points.

At a later date observer difference was tested in 3 observers who had never performed the test previously. The grading system was explained; scores were compared on two subjects and then the three inexperienced observers watched a series of 15 patients perform the U.E.F.T. (Table 5). These inexperienced observers were within 7 points in 29 of 30 tests (97 per cent).

Table 5. COMParison OF U.E.F.T. SCORES IN 15 PATIENTS (30 UPPER EXTRemities) By THREE OBSERVERS RECENTLY INSTRUCTED IN THE TEST AND ITS SCORING METHOD

\begin{tabular}{|c|c|c|c|c|c|c|c|c|c|}
\hline & \multirow{2}{*}{ Diagnosis } & \multicolumn{2}{|c|}{ Observer-1 } & \multicolumn{2}{|c|}{ Observer-2 } & \multicolumn{2}{|c|}{ Observer-3 } & \multicolumn{2}{|c|}{ Snread of scores } \\
\hline & & R. & L. & $\mathrm{R}$. & L. & R. & L. & R. & L. \\
\hline 1. & Rheumatoid A. & 99 & 96 & 99 & 96 & 99 & 96 & 0 & 0 \\
\hline 2. & Rheumatoid $\mathrm{A}$. & 84 & 80 & 91 & 83 & 86 & 81 & 7 & 3 \\
\hline 3. & Rheumatoid A. & 75 & 89 & 77 & 86 & 74 & 86 & 3 & 3 \\
\hline 4. & Rheumatoid A. & 16 & 21 & 22 & 19 & 22 & 22 & 6 & 3 \\
\hline 5. & Quadraplegia & 60 & 59 & 61 & 60 & 62 & 58 & 2 & 2 \\
\hline 6. & Quadraplegia & 55 & 56 & 60 & 54 & 57 & 54 & 5 & 2 \\
\hline 7. & Quadraplegia & 19 & 18 & 23 & 18 & 21 & 18 & 4 & 0 \\
\hline 8. & Quadraplegia & 51 & 33 & 56 & 38 & 57 & 34 & 6 & 5 \\
\hline 9. & Poliomyelitis & 96 & 94 & 90 & 94 & 89 & 93 & 7 & 1 \\
\hline 10. & Multiple sclerosis & 49 & 0 & 48 & 0 & 50 & 0 & 2 & 0 \\
\hline 11. & Cerebral palsy & 32 & 17 & 31 & 19 & 33 & 18 & 2 & 2 \\
\hline 12. & Cerebellar ataxy & 59 & 74 & 61 & 87 & 62 & 84 & 3 & 13 \\
\hline 13. & Wrist fracture & 99 & 34 & 99 & 32 & 99 & 35 & 0 & 3 \\
\hline 14. & Scleroderma & 99 & 95 & 99 & 95 & 99 & 96 & 0 & 1 \\
\hline 15. & Hand burn & 83 & 41 & 87 & 41 & 82 & 44 & 5 & 3 \\
\hline
\end{tabular}

\section{I SCU S I O N}

The U.E.F.T. and its scoring

The upper extremity function test described above attempts to determine what functions are impaired in various diseases and injuries of the upper extremity and how these functions change with advancing disease, surgery or other treatment. The test consists of performing certain stereotyped activities with the upper extremities. It is designed to assess severity of impairments. There are a number of tests to evaluate skill and speed of normal subjects with normal upper extremities, but the present test does not attempt to do more than estimate the function of the hand as it may be useful in ordinary activities of daily living. 
Previous attempts have been made to describe all hand activities as variations of a few underlying basic functions [1, 2, 5]. The description of normal hand function in terms of basic maneuvers is particularly important in prosthetic fabrication where only a few motions can be transmitted [6,7]. BREWERTON [8] has described the hand abnormalities seen in rheumatoid arthritis in terms of basic hand function. No one has attempted to design an overall test of upper extremity function on the basic maneuvers and to score it in quantitative terms.

NAPIER [9] and LANDSMEER [10] have described two types of grip, one when the object is held between the flexed fingers and the thumb lying more or less in the plane of the palm (power grip) and the other when an object is pinched between the flexor aspects of the fingers and the opposing thumb (precision grip).

In terms of the U.E.F.T, the functions of the upper extremity investigated are grasp, grip, pinch (fingers), placing, arm extension, supination, pronation (arm), forward flexion and abduction (shoulder). These words are defined in terms of the maneuvers carried out in the test. None of these activities is isolated from the total function of the extremity. That is, the grasp tests cannot be performed without wrist, arm and shoulder stabilizers. No activity tested is a 'discrete' [11-13] movement. Nearly every activity performed in the test brings into action the whole upper extremity and trunk. It is for this reason that the terms grasp, grip, pinch. placing, arm extension and flexion, supination and pronation, shoulder flexion and abduction must be defined in terms of the testing procedure.

Grasp is the maneuver used in lifting items 1,2,3 and 4 from their holders; grip is the maneuver of lifting the pipes from their positions; pinch consists of putting the spheres in their correct position and the washer over the nail; arm extension, supination and pronation, shoulder abduction and flexion likewise are included in placing all items on the shelf and in pouring the water from pitcher to glass and from glass to glass. To be sure, the pipes may be lifted from their position by the use of either grasp or pinch, but this will be noted during the evaluation. These deviations in performance of the stereotyped tests reveal the abnormalities, substitutions and modifications characteristic of different disabilities.

If one compares the list of activities in the hand evaluation test with the range of maneuvers which the normal person carries out daily, the list is extremely poverty stricken as a conspectus of behavior of the upper extremity. Nevertheless, in the analysis of the upper extremity in action, there can be split off from its total behavior fractional pieces which may be treated conveniently, though artificially, apart. The list finally selected by trial and error is believed to represent those maneuvers necessary for accomplishing the major activities of daily living appropriate to the upper extremity.

\section{Significance of changes in U.E.F.T. scores}

Changes in score on the individual subtests are the items of immediate importance in following a patient. That is, if a patient was unable to pick up the 5/32 in. ball-bearing between small finger and thumb (item 24) and place it on the shelf normally (score 3) initially, but was able to accomplish this movement after a time, one would conclude that there had been an improvement in this function. But does the improvement in this isolated activity indicate a significant improvement in overall function? Overall function depends on how the whole test is 
performed, and we cannot conclude that there was a significant improvement in overall function unless the total score increased. How much must the total score increase to indicate significant improvement in function?

We have concluded that the U.E.F.T. is reasonably well correlated with a standard hand activities of daily living test, gives consistent scores when repeated in patients with clinically stable disabilities and gives close agreement in score when administered by different observers.

We have assumed that an increase in score of 10 points represents significant improvement in what the patient is able to do with the hand in the activities of daily living. A drop of 10 points is assumed to represent a loss of significant function.

The test has been worked out to give nearly equal scoring points to the prehensile function (grasp, grip and pinch) and to the placing function (shoulder stability, abduction, flexion and extension of the shoulder, flexion and extension of the elbow, flexion, extension, pronation and supination of the wrist) of the upper extremity. Both of these functions have to be good to obtain a high score; if either is absent or badly impaired, the score will be low.

It would be impossible to say, however, that two patients with the same total score at any particular time have an equal degree of disability. Obviously, the prognosis for improvement, the possibility of use of prosthetic devices, the reaction of the patient to the impairment, vocational potential and a number of other factors are important in determining the degree of disability. It has been pointed out that the test attempts to measure function in relation to activities of daily living and has not been related to vocational activities of the upper extremity.

TABLE 6. TOTAL SCORFS IN SFVEral. AMPUTATIONS

\begin{tabular}{lc} 
& Total U.E.F.T. Score \\
\cline { 2 - 2 } Wrist & 0 \\
Three small fingers & 41 \\
Middle finger & 87 \\
Index finger and 2nd metacarpal & 84 \\
Thumb at metacarpal-phalangeal joint & 91 \\
Index finger at proximal interphalangeal joint & 93
\end{tabular}

Table 6 shows the total scores on a number of patients with amputations. These illustrations are selected because they are clear-cut and might be expected to give similar scores in similarly affected patients. In general, the impairment caused by amputation of a single finger at the metacarpal-phalangeal joint is not very great in relation to activities of daily living. The degree of impairment in function suggested by these scores is generally less than that outlined by the Committee on Medical Rating of Physical Impairment [14] for similar amputations. This disagreement is adequately explained by the fact that the latter is used in estimating situations in relation to industrial and vocational potential rather than activities of daily living potential.

The application of the U.E.F.T. to elderly patients

The study of elderly patients with multiple disabilities in the Baltimore City 
Hospital Infirmary shows the importance of thinking of upper extremity function in terms of the patient's total bodily physical and mental resources. In this group of patients, despite many severe upper extremity disabilities, the upper extremity impairments alone were generally insignificant in relation to the generalized diseases and impairments present. No patient was hospitalized for an isolated upper extremity impairment, nor would improvement in upper extremity function in these patients have increased vocational potential. This study does not demonstrate that the upper extremity impairments were unimportant in these patients, it merely indicates that upper extremity function must be placed in the perspective of the patient's total physical, mental and social resources.

\section{SUMMARY}

An evaluation of upper extremity function in patients with severe hand disabilities in terms of pinch, grasp, grip, elbow flexion and extension, forearm pronation and supination was performed and scored. Scores on this basic test correlated fairly well with scores on a conventional hand activities of daily living test. The test has sufficient reliability and consistency to measure improvement or deterioration in function when performed serially. Application of the test to a large number of nursing home type patients has shown that upper extremity activity is meaningless without knowledge of the patient's overall physical and mental functioning.

The hand evaluation can be used in properly selected patients to determine what functions of the upper extremity are impaired and need treatment. It can also be used to measure changes in hand function with advancing disease, surgical or other treatment.

\section{R E F E R E N C ES}

1. SCHLESINGER, G.: Die Mitarbeit des Ingenieurs bei der Durchbildung der Ersatzglieder, Verein. Deutsch. Ingen., Berlin Zt. schr. 61, 6, 1917.

2. SCHLESINGer, G.: Der Mechanische Aufbau der Kunstlichen Glieder in Ersatzglieder und Arbeitschilfen. Springer, Berlin, 1919.

3. Lifschitz, K. : Problems in the quantitative evaluation of patients with psychoses of the senium, J. Psychol. 49, 295, 1960.

4. Carroll, D.: The disability in hemiplegia caused by cerebrovascular disease, J. chron. Dis. 15, 179, 1962.

5. Wynn PARRY, C. B.: Rehabilitation of the Hand. Butterworth, London, 1958.

6. Conrrnt, R.: Prosthetic research and the engineering profession, Arrif. Limbs 1, 47 (Sept), 1954.

7. TAYLOR, C. L. and Schwarz, R. J.: The anatomy and mechanics of the human hand, Artif. Limbs 2, 22 (May), 1955.

8. Brewerton, D. A.: Hand deformities in rheumatoid disease, Ann. rheum. Dis. 16, 183, 1958.

9. NAPIER, J. R.: The prehensile movements of the human hand, J. Bone Jt Surg. 38B, 902. 1956.

10. Landsmeer, J. M. F.: Power grip and precision handling, Ann. rheum. Dis. 21, 164, 1962.

11. WALShE, F. M. R.: On the mode of representation of movements in the motor cortex. with special reference to "Convulsions beginning unilaterally" (Jackson), Brain 66, 104, 1943.

12. WALShe, F. M. R.: On the notion of the 'discrete movement' in willed motion, Brain 70, 93, 1947.

13. WALSHE, F. M. R.: On the role of the pyramidal system in willed movements, Brain 70 , $329,1947$.

14. A guide to the evaluation of permanent impairment of the extremities and back, J. Amer. med. Ass. Special Edition: Committee on Medical Rating of Physical Impairment. Feb. 15, 1958. 